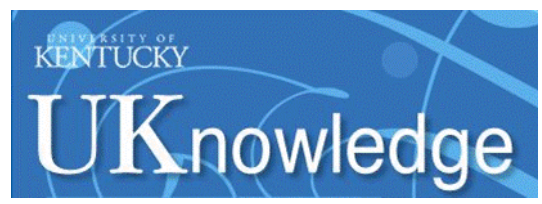

University of Kentucky

UKnowledge

$12-2019$

\title{
Family Conflict Observations and Outcomes among Adopted School-Age Children with Lesbian, Gay, and Heterosexual Parents
}

\author{
Rachel H. Farr \\ University of Kentucky, rachel.farr@uky.edu \\ Samuel T. Bruun \\ University of Kentucky, sbr268@g.uky.edu \\ Kyle A. Simon \\ University of Kentucky, kyle.a.simon15@gmail.com
}

Follow this and additional works at: https://uknowledge.uky.edu/psychology_facpub

Part of the Family, Life Course, and Society Commons, Lesbian, Gay, Bisexual, and Transgender Studies Commons, and the Social Psychology and Interaction Commons

Right click to open a feedback form in a new tab to let us know how this document benefits you.

\section{Repository Citation}

Farr, Rachel H.; Bruun, Samuel T.; and Simon, Kyle A., "Family Conflict Observations and Outcomes among Adopted School-Age Children with Lesbian, Gay, and Heterosexual Parents" (2019). Psychology Faculty Publications. 190.

https://uknowledge.uky.edu/psychology_facpub/190

This Article is brought to you for free and open access by the Psychology at UKnowledge. It has been accepted for inclusion in Psychology Faculty Publications by an authorized administrator of UKnowledge. For more information, please contact UKnowledge@lsv.uky.edu. 


\section{Family Conflict Observations and Outcomes among Adopted School-Age Children with Lesbian, Gay, and Heterosexual Parents}

Digital Object Identifier (DOI)

https://doi.org/10.1037/fam0000576

Notes/Citation Information

Published in Journal of Family Psychology, v. 33, no. 8, p. 965-974.

(c) American Psychological Association, 2019.

The copyright holder has granted the permission for posting the article here.

This paper is not the copy of record and may not exactly replicate the authoritative document published in the APA journal. Please do not copy or cite without author's permission. The final article is available, upon publication, at: https://doi.org/10.1037/fam0000576 
Family Conflict Observations and Outcomes among

Adopted School-age Children with Lesbian, Gay, and Heterosexual Parents

\author{
Rachel H. Farr, Samuel T. Bruun, and Kyle A. Simon \\ University of Kentucky
}

\title{
Acknowledgments:
}

This research was supported by funding from the American Psychological Foundation's Wayne F. Placek Grant awarded to Rachel H. Farr (Wave 2) and the Williams Institute at UCLA to Charlotte J. Patterson (Wave 1). The first author was also supported (Wave 2) by funds from the Rudd Family Foundation Chair in Psychology at the University of Massachusetts Amherst. We would like to thank the members of our research team who have contributed to the design and execution of the overall project, particularly our coding team, Jessica Cherry, Stefanie Jones, Alex Nelson, and Madison Yee. We are grateful to all the adoptive families who generously shared their experiences with us and have made this research possible. An earlier version of this paper was presented at the American Psychological Association (APA) Convention in 2017.

\section{Correspondence to:}

Rachel H. Farr, Ph.D.

Assistant Professor

University of Kentucky, Department of Psychology

171 Funkhouser Drive, 012-B Kastle Hall

Lexington, KY 40506-0044

Phone: (859) 257-4393

Fax: (859) 323-1979

rachel.farr@uky.edu

(C) 2019, American Psychological Association. This paper is not the copy of record and may not exactly replicate the final, authoritative version of the article. Please do not copy or cite without authors' permission. The final article will be available, upon publication, via its doi:10.1037/fam0000576 


\begin{abstract}
Children's externalizing problems are associated with family conflict among children and their biological parents, yet these linkages have remained unexamined among adoptive or lesbian and gay (LG) parent families. Investigating family processes facilitative of adjustment among adoptees, who face unique developmental challenges, is warranted. This multi-method study of 96 (26 lesbian, 29 gay, 41 heterosexual parent) adoptive families examined observations of adoptive family conflict and associations with child adjustment and feelings about adoption (children's $M_{a g e}=8$ years). The sample was recruited from five private, domestic infant adoption agencies across the United States. Parents and children reported about children's externalizing problems and feelings about adoption, respectively. Observations of family conflict interaction were rated from videotaped family discussions. Family interactions were associated with children's behavioral and adoption-specific adjustment, yet ANOVA and HLM analyses revealed no differences by parental sexual orientation in family dynamics (i.e., negativity/conflict, positive affect, cohesiveness) or child outcomes. Parents generally reported children to have few externalizing behaviors. Children reported positive feelings, moderate preoccupation, and low negativity about their adoption. These findings extend the family systems literature about conflict and child development among diverse families with sexual minority parents and adopted children. Practitioners who work with adoptive and sexual minority parent families can encourage positive and cohesive family interactions in supporting children's adjustment.
\end{abstract}

Keywords: adoption, child externalizing behaviors, family interactions, lesbian and gay parenting, parent-child conflict. 


\section{Family Conflict Observations and Outcomes among}

Adopted School-age Children with Lesbian, Gay, and Heterosexual Parents

Growing numbers of families in the United States include lesbian and gay (LG) parents and adopted children (Gates, 2013; Goldberg \& Conron, 2018). Research about whether and how LG parents influence children's development has consistently shown that children born to and adopted by sexual minority and heterosexual parents are similarly well-adjusted (Biblarz \& Stacey, 2010; Farr, 2017; Fedewa, Black, \& Ahn, 2015). Fewer studies of LG or adoptive parent households, however, have targeted overall family functioning and possible associations with children's adjustment (e.g., Farr, 2017). This is despite three disparate bodies of research demonstrating that: (1) LG parents with young children engage in different coparenting practices than their heterosexual counterparts (e.g., Farr \& Patterson, 2013), (2) adopted children may be more at risk than nonadopted children for externalizing problems (Grotevant, McRoy, Wrobel, \& Ayers-Lopez, 2013; Grotevant, Rueter, Von Korff, \& Gonzalez, 2011), and (3) family conflict is linked with child maladjustment, at least among heterosexual parents and biologically-related children (Davies, Martin, \& Cummings, 2018; El-Sheikh, Cummings, \& Reiter, 1996). Thus, our two-fold objective was to examine whether (1) positivity, negativity, and cohesiveness during family interaction would be related to school-age children's behavioral and adoption-specific adjustment, and (2) family conflict observations, child outcomes, or their associations differed among LG and heterosexual adoptive parent families. We next provide an overview, grounded in

family systems theory, of relevant research about family conflict and child outcomes, particularly those focused on observational methods, sexual minority parent families, and adopted children.

\section{Associations between Family Conflict and Child Outcomes}


Family systems theory states that overall family functioning is influential to its individual members; individuals cannot be understood apart from the family context (Cox \& Paley, 1997; Minuchin, 1988). Thus, promoting family harmony has benefits for individual and whole family outcomes (Van Doorn, Branje, \& Meeus, 2008). Research among heterosexual parent families suggests that low family conflict is linked with positive child adjustment in childhood and adolescence (e.g., Cummings, Koss, \& Davies, 2015; Demby, Riggs, \& Kaminski, 2017; ElSheikh et al., 1996). In addition, cross-cultural research in the US, China, and Saudi Arabia indicates that family relational closeness is highest among adult children who report cohesive family conflict interactions, characterized by collaboration and compromise (Guan \& Li, 2017).

Observational methods have often been used to investigate broad family functioning, including managing conflict. These studies generally involve video-recordings of commonplace and low-intensity family disagreements, revealing that negativity (i.e., hostility) among parents is associated with negative emotional child outcomes across developmental stages from toddlerhood to adolescence (Davies, Coe, Martin, Sturge-Apple, \& Cummings, 2015; Feinberg, Kan, \& Goslin, 2009; Keller, Cummings, Peterson, \& Davies, 2009). Many studies in this area have focused particularly on interparental or parent-child conflict (Davies et al., 2015; Keller et al., 2009), and fewer overall have focused on conflict within the family as a whole (Cummings et al., 2015; Demby et al., 2017). Observational studies focusing on whole family interaction patterns during conflict have uncovered associations of fewer behavior problems among preadolescent children when families demonstrate more positive affect, less negativity, and more cohesiveness (i.e., general unity; Demby et al., 2017; Shigeto, Mangelsdorf, \& Brown, 2014). Many of these studies of family conflict observations relevant to children's adjustment have primarily been conducted among heterosexual parent families with biologically-related 
children (Branje, Van Doorn, van der Valk, \& Meeus, 2009; Schoppe, Mangelsdorf, \& Frosch, 2001; Singh \& Nayak, 2016). Few observational studies have featured adoptive or LG parent families, yet available evidence has revealed some unique family communication patterns related to adoption status at least among heterosexual parent families with adolescents (Rueter \& Koerner, 2008), as well as coparenting dynamics that are linked with child externalizing problems among LG and heterosexual adoptive parenting couples (Farr \& Patterson, 2013). No study, to our knowledge, has specifically and simultaneously addressed topics of how LG adoptive parent families manage conflict and how these behaviors may relate to child outcomes. Thus, further examination of LG and heterosexual adoptive parent families is needed about how family functioning among diverse groups may be associated with young children's development.

The developmental trajectories of adopted children, including those who have LG parents, are important to uniquely consider, as these children face several distinct developmental challenges in understanding and contextualizing their adoptive status. Previous researchers note that adopted children spend differing amounts of time and energy thinking about their adoption (i.e., often termed "preoccupation with adoption") and adopted children also show varying levels of curiosity about their biological origins, heritage, and family members (Kohler, Grotevant, \& McRoy, 2002; Tan \& Jordan-Arthur, 2012; Wrobel, Grotevant, \& McRoy, 2004). Adopted children must also manage the psychological presence of, and often direct relationships with both adoptive and birth families (Brodzinsky, 2011; Grotevant et al., 2013). Perhaps relatedly, adopted children have also been posited as at risk for externalizing problems as compared to their nonadopted peers (Grotevant et al., 2013; Grotevant et al., 2011).

Consistent with a family systems perspective, we know that satisfactory communication between children's birth and adoptive families shares associations with children's more complete 
and positive understanding of adoption, better feelings about their adoption, and fewer externalizing problems during adolescence - at least among adoptive families headed by heterosexual parents (Brodzinsky, 2006; Grotevant et al., 2011; Tieman, van der Ende, \& Verhulst, 2008). In the context of positive reports of family functioning, adolescent adoptees often describe positive feelings about their adoption, including heightened curiosity or preoccupation (Wrobel et al., 2004). In addition, research has also demonstrated that sibling relationships, as well as parent-child relationships, also play a role in influencing adoptees' externalizing behaviors and positive feelings about adoption during adolescence and early adulthood (Farr, Flood, \& Grotevant, 2016). Thus, it is reasonable to theorize that whole adoptive family interactions could share associations with preadolescent children's behavioral and adoption-specific adjustment. Little additional information exists, however, about the role of observed family interactions, including those that occur during family conflict, and possible associations with adopted children's externalizing behaviors and feelings about adoption. Even less research has been conducted on these topics among adoptive families headed by LG parents.

\section{Research on LG Parent Families and Adopted Children}

LG parents are seven times more likely to adopt than are heterosexual parents (Goldberg \& Conron, 2018), so the question of whether family interaction patterns and related child outcomes among LG adoptive parent families are similar or different to those previously demonstrated in the literature is imperative to examine. Existing research has demonstrated that children (including adopted children) with LG parents share very similar, or even more positive, developmental outcomes as compared to children with heterosexual parents (Biblarz \& Stacey, 2010; Fedewa et al., 2015; Golombok et al., 2014). Research about LG parent families has less often included studies about overall family functioning using observational data. Such data, 
when available, provide additional understanding about young children's positive development in LG parent families. For instance, researchers have uncovered significant associations between supportive parenting or coparenting practices and fewer child behavior problems (e.g., Bos, van Balen, \& van den Boom, 2007), including among LG parent families specifically with adopted children (Farr \& Patterson, 2013; Golombok et al., 2014).

Some studies have directly attended to the perspectives of children and adolescents adopted by LG parents, which have indicated positive feelings about adoption as well as about having LG parents (Cody, Farr, McRoy, Ayers-Lopez, \& Ledesma, 2017; Farr, Crain, Oakley, Cashen, \& Garber, 2016; Gianino, Goldberg, \& Lewis, 2009). These studies have focused on qualitative analyses of individual interview data, and have not been extended to quantitative data about children's feelings about adoption and their possible associations with other family dynamics (such as family conflict communication) among a diverse sample of adoptive families headed by LG and heterosexual parents. The broader body of literature about LG parent families, including those with adopted children, suggests that these families may embody unique strengths in terms of family communication (e.g., as related to preparation for bias related to heterosexism, racism, adoptism, etc.; Gianino et al., 2009; Goldberg \& Smith, 2016) as well as resilience in individual outcomes in the context of adversity (i.e., facing stigma and discrimination; Farr, Crain et al., 2016; van Gelderen, Gartrell, Bos, \& Hermanns, 2013). Thus, it is vital to understand more, employing a broader and more rigorous array of assessments (i.e., child and parent reports, observational data) about how these families navigate difficult conversations together and whether these interaction dynamics relate to young children's adjustment.

\section{Developmental Context of Middle Childhood}


Given advances that children experience in their social perspective-taking abilities during middle childhood, from 6-12 years, children's adjustment may be particularly vulnerable at this time to the effects of family conflict (Davies et al., 2018; Demby et al., 2017). Some scholars posit that middle childhood is a "switch point" for children in translating stressful experiences into particular coping strategies for managing that stress or conflict (Del Giudice, Angeleri, \& Manera, 2009). As such, this developmental stage may be one of heightened sensitivity to family conflict with long-term effects on adjustment (Davies, Martin, \& Sturge-Apple, 2016).

Among adopted children, it is during middle childhood that they develop the cognitive capacity to grapple with complex issues about adoption (Brodzinsky, 2011). Children begin to consider their birth parents' motivations for placing them for adoption, the complexities of biological and emotional family ties, and they may seek more information about their adoption than they had earlier (Brodzinsky, 2011). Openness about adoption, in addition to broad communicative openness within families, can make this process of understanding adoption easier (Brodzinsky, 2006). No studies to our knowledge, however, have examined how other familylevel traits, such as qualities of managing family disagreements, may relate to preadolescent children's feelings about their adoption. Taken together, research is needed to explore how adoptive sexual minority parent families manage conflict, as well as how these interactions may be associated with children's behavioral adjustment and perceptions about their adoption.

\section{The Current Study}

This study addressed several gaps in family systems research, primarily by including a sample of LG adoptive parent families, observations of family interaction, and analyses about how family dynamics may be associated with children's behavioral and adoption-specific outcomes. We used a multi-method, multi-informant design with observational data and reports 
from children and parents to minimize self-report bias and directly examine family behaviors; previous research has demonstrated the importance of observational data (in addition to, or beyond self-report data) to more comprehensively assess dyadic and triadic family interaction patterns and associations with children's adjustment (Favez, Widmer, Frascarolo, \& Doan, 2019; Teubert \& Pinquart, 2010).

We had two main research questions:

1. Are family conflict interactions and children's outcomes associated among this sample of adoptive families with preadolescent children and diverse in parental sexual orientation? As previous research has shown connections between successful family conflict resolution and positive outcomes for young children (El-Sheikh et al., 1996; Richmond \& Stocker, 2006), we predicted that lower negativity, higher positive affect, and greater cohesiveness during a family disagreement task would be associated with fewer child externalizing behaviors (Demby et al., 2017). There are no observational studies (to our knowledge) addressing family conflict and adoption-specific outcomes. Based on related research (e.g., Farr \& Patterson, 2013; Grotevant et al., 2011; Tieman et al., 2008; Wrobel et al., 2004), however, we anticipated that family interactions and children's feelings about adoption would be significantly associated. As this was an exploratory hypothesis, we did not generate more specific predictions.

2. Are there differences in family conflict interactions (i.e., family negativity, positive affect, cohesiveness), in child outcomes, or in associations between conflict interactions and child outcomes among families with LG or heterosexual parents? Given previous research (Biblarz \& Stacey, 2010; Farr, 2017; Fedewa et al., 2015; Goldberg \& Smith, 2013), we hypothesized no significant differences by family type (i.e., LG and heterosexual parents) in observed family dynamics, in children's outcomes, nor in associations between the two. 


\section{Method}

\section{Participants}

Participants were 96 families who provided questionnaire and observational data from the second wave (W2; collected in 2013-2014) of a larger longitudinal study (Farr, 2017; Farr \& Patterson, 2013; see Table 1 for demographic characteristics). Each family had one target child (the focus of analyses) between 5-12 years $\left(M_{\text {age }}=8\right)$. The target child was the oldest adopted child within 1-5 years old at the first wave (W1) of data collection (in 2007-2009). All children (48 girls, 48 boys) were adopted in infancy from one of five private adoption agencies across the US who had placed children with LG and heterosexual parents. No children had prior placements, and all families were initially invited to participate through their adoption agency. Families generally represent high socioeconomic status (SES) and close to half (46\%) had completed transracial adoptions. While most adoptive parents who participated at W2 are White (81\%), most adopted children represent racial/ethnic minority backgrounds (38\% White, 32\% Black, 25\% Multi-ethnic, 3\% Latino/Hispanic, 2\% other racial/ethnic identities). Families live across the US in 1 of 12 states in the South and both Coasts. Although fewer than half of families had more than one child at W1 (Farr \& Patterson, 2013), by W2, 63\% of participating families had two or more children. To encourage whole family conversation that felt natural and realistic, as well as to accurately capture family-level functioning among families with multiple children, siblings were invited to participate if the families so chose (Richmond \& Stocker, 2006). Thus, siblings, when present, frequently participated in family interaction tasks. Specifically, of the families who provided observational data $(n=90)$ and also had more than one child, $61 \%$ completed the family conflict interaction task with the target child and a sibling.

\section{Measures and Procedure}


Families were visited in their homes by the first author, where the observation tasks were completed. Individual parents and children completed questionnaires using Qualtrics. The first author assisted children by reading all questions aloud to them. Before participating, parents and children provided informed consent and assent, respectively; no financial compensation was provided. The Institutional Review Boards of the University of Virginia, University of Massachusetts Amherst, and University of Kentucky approved the study.

Observations of family interaction. To assess how families navigate conflict discussion, parents and children were asked to discuss a recent disagreement and work towards resolution for approximately 10 minutes - a video-recorded task used to elicit a range of emotions and problem-solving behaviors. This type of observational task is designed to facilitate and coordinate the perspectives of multiple family members, showcasing power "sharing" versus "wielding" dynamics that are typical during family conflict interactions (e.g., Favez et al., 2019). To select a topic, parents individually completed the Issues Checklist (Robin \& Foster, 1989) prior to the interaction. We made some wording modifications for parents of preadolescent children and 8 of 45 original items (e.g., "Going on dates", "How money is spent") were omitted (as they were originally intended for parents of adolescents). Parents responded "Yes/No" to whether they had discussed each of 37 items (e.g., "Doing homework", "Putting away clothes," "Cleaning bedroom") with their child in the last four weeks. Parents also listed the "top 3 issues" which were then used as possible conversation topics during the observational task. The most common disagreements were related to school, sibling fighting, and time spent on TV, internet, and video games.

To assess family interactions in the context of parent-child disagreements, we used the System for Coding Interactions and Family Functioning (SCIFF; Lindahl \& Malik, 2001). The 
SCIFF is a macro-level coding scheme that has been effective in identifying how family-level traits (i.e., negativity/conflict, positive affect, and cohesiveness) are linked with children's behavioral adjustment and emotional health (Cummings et al., 2015; Demby et al., 2017; Shigeto et al., 2014). Thus, we included the Negativity/Conflict, Cohesiveness, and Positive Affect subscales. Negativity/Conflict assesses the degree to which parent-child interactions are hostile or tense, including body language and tone. Cohesiveness measures how well the family works together to resolve conflict, including how well families stay “on task". Finally, Positive Affect measures pleasant emotional tone in the family's interactions, including body language, tone, and markers such as smiles and laughter. All items are rated by coders on a 1-5 Likert scale $(1=$ very low, $5=$ very high), indicating the degree to which that element characterized the interaction (Lindahl \& Malik, 2001).

Undergraduate research assistants were trained to rate families' interactions. Complete observational data were provided by 90 of 96 families. Each interaction was rated by at least two trained coders, who met weekly to resolve discrepancies through discussion. Reliability was excellent; intraclass correlation coefficients averaging .84 across the 3 observational variables.

Child behavioral outcomes. The externalizing behavior subscale of the Child Behavioral Checklist for ages 6-18 (Achenbach \& Rescorla, 2001) was used to assess children's adjustment at W2. Both parents in each family generally completed this measure; they rated 42 externalizing problems on a $0-2$ scale about their child $(0=$ not true, $1=$ somewhat or sometimes true, 2 = very true or often true; e.g., "Disobedient at home," "Gets in many fights," "Lying or cheating"). Scores are calculated through aggregating all items, which are then converted into standardized $T$ scores adjusted for child sex and age. Higher $T$ scores indicate greater problems; 
scores 64 or higher indicate clinical levels (Achenbach \& Rescorla, 2001). Cronbach's alpha for externalizing items was .91. Scores were available for children in 95 of 96 families.

Feelings about adoption. Children's feelings about their own adoption were assessed with the Adoption Dynamics Questionnaire (ADQ; Benson, Sharma, \& Roehlkepartain, 1994). This scale is comprised of 3 subscales: positive affect about own adoption ( 20 items; e.g., "I think my parents are happy they adopted me", "I'm glad my parents adopted me"), negative experiences with adoption (7 items; e.g., "I get tired of having to explain adoption to people", "I get teased about being adopted"), and preoccupation with adoption (3 items; e.g., "How often do you think about your birth mother?", "How often do you think about adoption?”). The first two subscales are rated from 1 ("Not true or strongly disagree or never") to 5 ("Always true or strongly agree or always"). The preoccupation subscale is rated from 1 ("Never") to 7 ("Every day"). Items are averaged for each subscale; higher numbers indicate greater positive affect, negative experiences, and preoccupation, respectively. Originally developed for adolescents, the ADQ was modified for younger children by omitting 14 of 17 preoccupation items (e.g., "I wish I knew more about my medical history"). Cronbach's alphas averaged .72 across subscales, demonstrating good internal consistency. Of the 96 children at W2, 88 completed the ADQ.

Power analyses. We conducted power analyses (G*Power; Faul, Erdfelder, Lang A.-G., $\&$ Buchner, 2007) for analyses of interest ( $\alpha=.05, N=96$ families). For bivariate correlations, power was .99 for large, .85 for medium, and .16 for small effects. For one-way ANOVA (3 groups), power was .94 for large, .57 for medium, and .13 for small effects. For multiple regression ( 3 predictors), power was .99 for large, .89 for medium, and .18 for small effects. Thus, analyses were mostly powered to detect medium to large effects.

\section{Results}




\section{Descriptive Information and Preliminary Analyses}

Families generally displayed high cohesiveness and positive affect, with moderate negativity/conflict. Children's mean externalizing behaviors were below clinical levels. Children also tended to have very positive feelings, few negative experiences, and moderate preoccupation related to their adoption. See Table 2 for all descriptive information.

Preliminary analyses revealed that the target child's age and sex, as well as the presence and participation of siblings in each family were not significantly associated with any observational variables; thus, these demographic characteristics were not considered in subsequent analyses. Similarly, few demographic differences characterized families as a function of parental sexual orientation. Gay father families reported greater household income on average than the other two family groups, yet preliminary analyses indicated that income was unrelated to all study variables. Although some W1 couples were no longer together by W2 (and with lesbian couples more likely to have dissolved their relationship than gay or heterosexual couples; Farr, 2017), all families who provided data were included. With the unexpected exception of higher mean scores in observed family cohesiveness among separated-parent families, no other significant differences were found as a function of W2 couple status. To ensure we did not miss differential findings based on couple relationship status, we ran all our analyses two ways: (1) including all families and (2) excluding families who had experienced couple separation. No significant differences in the patterns of results emerged; thus, we maintained our analyses with all available data from participating families.

\section{Associations between Family Observations and Child Outcomes}

Consistent with our first hypothesis, several associations between family observations and child outcomes were uncovered (see Table 3 for correlations among all study variables). 
Although externalizing behaviors (averaged among parents within the same families) were not correlated with positive affect during family interaction, they were correlated with family negativity/conflict, $r(89)=.26, p=.013-$ families with greater negative emotions during conflict had children with more externalizing problems. Externalizing behaviors were also correlated with cohesiveness, $r(89)=-.34, p=.001$, such that families who displayed greater unity in their problem-solving had children with fewer problems.

Children's positive affect about their adoption and negativity/conflict were correlated, $r(83)=-.23, p=.036$, such that conflictual family interactions were linked with less positive adoption feelings. Children's positive adoption feelings and cohesiveness were also correlated, $r(83)=.23, p=.036$; families who displayed greater unity during conflict had children who felt more positively about adoption. Children's positive affect about adoption and observed family positive affect were associated, $r(83)=.30, p=.007-$ families who displayed positive emotions had children who reported greater positivity about their adoption. Children's negative experiences with adoption were not significantly correlated with any of the three observed family conflict variables, yet children's preoccupation with adoption history was significantly associated with family cohesiveness, $r(82)=.25, p=.024$.

Next, we investigated our first hypothesis about whether observed family interaction variables were associated with child outcomes using a multivariate approach, specifically for outcomes in which multiple family interaction variables were significantly associated. We employed Hierarchical Linear Modeling (HLM; Raudenbush \& Bryk, 2002) and multiple regression to examine externalizing problems and positive affect about adoption as dependent variables, respectively. HLM (represented by equation below) was employed (using HLM7; Raudenbush, Bryk, Cheong, Congdon, \& du Toit, 2011) to account for potential covariance in 
dual parent reports within families; and missing data (generally fewer than $5 \%$ of cases across variables) were handled with full maximum likelihood. Level 1 represents the calculation for parents' reports of children's externalizing problems, $Y_{i j}$. $\beta_{0 j}$ represents the random intercept and $e_{i j}$ is the error term. The Level 2 equation represents a comparison of those averages for externalizing behaviors. The $u_{0 j}$ coefficient controls for the nonindependent data structure. We simultaneously entered observed family negativity/conflict and cohesiveness (based on correlational results) as independent variables to statistically predict children's externalizing problems.

Level 1: $Y_{i j}($ Externalizing $)=\beta_{0 j}+\beta_{1 j}($ Negativity/Conflict $)+\beta_{2 j}($ Cohesiveness $)+e_{i j}$ Level 2: $\beta_{0 j}=\gamma_{00}+u_{0 j}$

$$
\begin{aligned}
& \beta_{1 j}=\gamma_{10}+u_{10 j} \\
& \beta_{2 j}=\gamma_{20}+u_{20 j}
\end{aligned}
$$

The overall HLM model was significant, $F(2,86)=5.76, p=.004, R^{2}=.10$, and greater family cohesiveness (but not lower negativity/conflict) emerged as significant in predicting fewer externalizing behaviors. Specifically, the HLM analysis revealed that family cohesiveness during conflict significantly predicted children's externalizing behaviors, $t$-ratio( 83$)=-2.26, p=$ .027 , but family negativity/conflict did not, $t$-ratio( $(83)=.78, p=.439$. Using the average of parents' reports within families for children's externalizing problems, multiple regression results were consistent with HLM.

Simultaneous multiple regression was used to assess whether family cohesiveness, positive affect, and negativity/conflict would statistically predict children's positive adoption feelings. Although the overall model proved significant, $F(3,79)=2.86, p=.042 ; R^{2}=.06$, no individual predictor was significantly associated with children's positive adoption feelings. It is 
important to note that although family observations statistically predicted child outcomes in the preceding analyses, directionality of effects cannot be determined with these cross-sectional data.

\section{Family Type Differences}

Next, we investigated our second hypothesis by using one-way analysis of variance tests (ANOVA) to compare observed variables and child outcomes by family type (lesbian, gay, and heterosexual parent families). We also included Bayesian analyses to supplement traditional hypothesis testing. A Bayes Factor $\left(\mathrm{BF}_{01}\right)$ of 1-3 indicates anecdotal evidence and $\mathrm{BF}_{01}$ of $3-10$ indicates substantial evidence for the null hypothesis (i.e., $\mathrm{BF}_{01}=3$ indicates that the data are 3 times more likely to support the null rather than alternative hypothesis; Jarosz \& Wiley, 2014). Across variables, and consistent with our second hypothesis, there were no differences in family interactions nor child outcomes as a function of parental sexual orientation; this was supported by the Bayes factors indicating substantially greater likelihood for the null over alternate model (Jarosz \& Wiley, 2014; see Table 2). Finally, we tested whether correlations among observed family variables and child outcomes differed by family type by using Fisher's $r$-to- $z$ transformations (Diedenhofen \& Musch, 2015). In no case were the differences significant between correlations among lesbian, gay, and heterosexual parent families.

\section{Discussion}

Our findings contribute to theory and empiricism surrounding family systems research among adoptive LG and heterosexual parent families. Previous research including observations of family interaction has not often focused on these family systems, yet this study reveals information about family functioning and associated child outcomes among adoptive LG parent families. Consistent with outcomes among heterosexual parent families (Davies et al., 2015; Demby et al., 2017; Teubert \& Pinquart, 2010), and adoptive LG parent families (Goldberg \& 
Smith, 2013), our central finding was that children's broad and adoption-specific outcomes were associated with dynamics of family conflict interaction, regardless of parental sexual orientation.

Our results underscore that children's externalizing behaviors were associated with qualities of family interaction, particularly cohesiveness. Lower cohesiveness was associated with behavior problems, as has been found among other families with adolescent children (e.g., Richmond \& Stocker, 2006), yet family negativity was not. Although negativity was correlated with externalizing problems, cohesiveness was more strongly associated when simultaneously considered. This may indicate the unique importance of family unity in resolving disagreements in its relation to children's behavioral adjustment, and perhaps particularly among adoptive sexual minority parent families (Brodzinsky, 2006; Guan \& Li, 2017). That this sample was characterized by relatively low negativity during interaction should be acknowledged. More intensely negative family interactions would likely impact child behavior (Schoppe et al., 2001).

Our findings also indicate, for the first time to our knowledge, that overall family functioning is significantly related to adoption-specific child outcomes. Family cohesiveness, positive affect, and negativity during conflict all correlated with children's positive adoption feelings. Observed family cohesiveness was also significantly positively correlated with children's preoccupation with adoption. The regression model of the three observed family-level variables onto children's positive adoption feelings was significant despite no significant individual predictors. Thus, broad qualities of family interaction, including cohesiveness, may be important to children's perceptions about their adoption. Cohesive families who function effectively during conflict may facilitate more successful family communication about adoption. As children in this sample were found to be moderately preoccupied with adoption, on average, this may reflect a general curiosity and inquisitiveness about their adoption during this 
developmental stage of middle childhood (Kohler et al., 2002; Wrobel et al., 2004). Thus, in the context of family cohesiveness, children curious about their adoption may feel comfortable discussing it and asking questions. They may more readily acknowledge their thoughts about their birth parents, as well as feel more positively about being adopted (Le Mare \& Audet, 2011).

Indeed, research has indicated several positive outcomes related to adoptive identity development among adoptees in families who regularly discuss adoption in responsive and supportive ways. For instance, families who encourage their children to openly discuss adoption and ask questions through natural, free-flowing conversational exchanges tend to best support the identity development of their children (Colaner \& Soliz, 2015). Von Korff and Grotevant (2011) also have shown longitudinally that, among adoptees from adolescence to emerging adults, more frequent adoption-related conversation in families is linked with adoptive identity development. Among adult adoptees, research has demonstrated that greater adoption communication openness within families is associated with lower adoption preoccupation and the general communication environment provided by adoptive families tends to be associated both with adoptive identity and self-esteem outcomes (Horstman, Colaner, \& Rittenour, 2016). Preoccupation was moderate, on average, among Horstman et al.'s sample, as it was in the current sample. The construct of preoccupation, however, was defined slightly differently by Horstman and colleagues - as an over-commitment to one's adoptive status - and it was measured with different items than were used in the current study. In contrast, in a study of adolescent adoptees who responded to the same preoccupation items as did the children in our sample, adoptees who demonstrated moderate or low levels of adoption preoccupation also reported greater parent-child closeness than did those who showed high adoption preoccupation (Kohler et al., 2002). Moreover, similar patterns of communication, closeness, and positive 
feelings have been observed in family discussions of other difficult topics (Guan \& Li, 2017). Thus, adopted children in this sample may feel safer expressing more complex feelings or experiences in family environments characterized by greater cohesiveness (Demby et al., 2017).

Of course, since these data are cross-sectional, the reverse pattern of findings could also be true - children who feel positively about their adoption may contribute to effective family communication and overall family cohesiveness. Regardless, our findings broaden previous research indicating associations between familial openness during conflict and positive child outcomes, specifically among diverse adoptive families headed by LG and heterosexual parents with school-age children.

In attempting to resolve conflicts, families displayed greater positive affect and cohesiveness than negativity and conflict, regardless of parental sexual orientation. This is noteworthy, given the emphasis of previous research on ensuring children have positive models for conflict resolution (e.g., Feinberg et al., 2009). LG parents did not differ from heterosexual parents in navigating family disagreements, with similar levels of cohesiveness, positive affect, and negativity and conflict observed among families. This aligns with research indicating few differences in parenting and family relationships among LG and heterosexual parent families (Biblarz \& Stacey, 2010; Farr, 2017; Golombok et al., 2014; Golombok et al., 2018). It is a first (to our knowledge), however, that these similarities have been demonstrated in the context of family conflict among LG and heterosexual parent adoptive families with school-age children.

Across the sample, children were reported by their parents to have relatively low levels of externalizing behavior problems, which contrasts with the notion that adopted children are at risk for psychopathology - particularly externalizing problems (Grotevant et al., 2011). It should be acknowledged, however, that the low level of externalizing problems could also reflect the 
homogeneity in this sample (i.e., relatively high family SES, all children adopted via private domestic infant adoption) or an issue related to parent reports (some parents could be reluctant to describe their children as having behavioral challenges). More research is necessary to address these potential limitations of our results, but we have reported elsewhere that children's teachers, as well as their parents, agree that children in this sample on average show low levels of behavior problems (Farr, 2017).

Our findings are also consistent with the literature indicating that children with LG and heterosexual parents are comparably well-adjusted, despite ongoing social controversy (Biblarz \& Stacey, 2010; Fedewa et al., 2015). Furthermore, this is the first study to our knowledge directly assessing children's perspectives about adoption among LG and heterosexual parent families. Children across family types felt positively about their adoption, reported few negative experiences, and noted moderate levels of preoccupation. Findings were comparable to means reported among samples of adolescent adoptees (Tan \& Jordan-Arthur, 2012; Wrobel et al., 2004), with both positive affect and preoccupation somewhat higher among our sample of adoptees in middle childhood (although studies with older adoptees have included versions of the Adoption Dynamics Questionnaire with more preoccupation items). As no study that we know of has specifically addressed this topic among a sample of adopted children with sexual minority and heterosexual parents, our results are noteworthy in indicating that these school-age adoptees report positive perceptions about their adoption regardless of their parents' sexual orientation. Finally, in no case were associations between family conflict interactions and child outcomes significantly different as a function of parental sexual orientation. Thus, taken together, sexual minority and heterosexual parents appear equally capable in providing family environments that 
foster well-adjusted adopted children, aligned with earlier research (e.g., Goldberg \& Smith, 2013), and also extending it to feelings about adoption.

\section{Strengths and Limitations}

This study adds to the literature by examining adoption-specific child outcomes in the context of family systems theory, which posits that children's development cannot be understood without considering influences of the whole family (Cox \& Paley, 1997). Data from multiple sources provided a richer picture of factors influencing child adjustment. Participation of LG and heterosexual parents allowed for cross-comparisons underrepresented in family systems research.

Some limitations should also be noted. The data are cross-sectional; directionality of effects cannot be determined. While our relatively high-SES sample is representative of families who complete private domestic adoptions, future research should consider how SES, parental sexual orientation, race, and varying pathways to parenthood intersect with family dynamics and child development. For instance, the majority of adoptive placements in the US today are via public domestic adoptions through the child welfare system (Farr \& Grotevant, 2019). Children adopted from foster care are often older and have experienced adversity in the form of abuse, neglect, or other trauma (Farr \& Grotevant, 2019). As such, dynamics of managing family conflict are likely different and more complex among these adoptive families as compared to the sample in this study; caution should be taken in generalizations of these findings to adoptive families who have adopted through different pathways than private domestic infant adoption. We also did not study other adoption-related variables, such as birth family contact, as related to child adjustment or family interactions. Indeed, openness between birth and adoptive families is generally linked with positive child outcomes (Grotevant et al., 2013).

\section{Implications and Conclusion}


Our findings align with and extend previous research, demonstrating that effective family conflict resolution and positive child outcomes are associated among adoptive LG parent families (Golombok et al. 2014; Teubert \& Pinquart, 2010). Notably, these outcomes included children's feelings about their adoption, a variable not yet considered within the conflict resolution or family systems literatures. Our findings may support practitioners working with adoptive families about how open, positive, and cohesive family communication may encourage children's positive adoption feelings as well as help them express questions related to their adoption (and vice versa). The results could also inform law and policy surrounding adoptive LG parent families. Although same-sex marriage rights have made adoption more feasible for sexual minority parents in the US, legal and practical barriers remain (Farr \& Goldberg, 2018; Harris, 2017). Our results about well-adjusted children in well-functioning families suggest no empirical justification for obstacles to adoption by sexual minority adults. The findings expand our understanding about family conflict and overall family functioning among diverse adoptive families, highlighting positive parenting, family functioning, and child adjustment. How families manage conflict appears to be more strongly associated than parental sexual orientation with adopted children's outcomes, including those broadly related to behavioral adjustment as well as those specifically related to feelings about one's own adoption. 


\section{References}

Achenbach, T. M., \& Rescorla, L. A. (2001). Manual for the ASEBA school-age forms \& profiles. Burlington, VT: University of Vermont, Research Center for Children, Youth, \& Families.

Benson, P. L., Sharma, A. R., \& Roehlkepartain, E. C. (1994). Growing up adopted: A portrait of adolescents and their families. Minneapolis, MN: Search Institute.

Biblarz, T. J., \& Stacey, J. (2010). How does the gender of parents matter? Journal of Marriage and Family, 72, 3-22. doi:10.1111/j.1741-3737.2009.00678.x

Bos, H. W., van Balen, F., \& van den Boom, D. C. (2007). Child adjustment and parenting in planned lesbian-parent families. American Journal of Orthopsychiatry, 77, 38-48. doi:10.1037/0002-9432.77.I.38

Branje, S. J., van Doorn, M., van der Valk, I., \& Meeus, W. (2009). Parent-adolescent conflicts, conflict resolution types, and adolescent adjustment. Journal of Applied Developmental Psychology, 30, 195-204. doi:10.1016/j.appdev.2008.12.004

Brodzinsky, D. (2006). Family structural openness and communication openness as predictors in the adjustment of adopted children. Adoption Quarterly, 9, 1-18. doi:10.1300/J145v09n04_01

Brodzinsky, D. M. (2011). Children's understanding of adoption: Developmental and clinical implications. Professional Psychology: Research and Practice, 42, 200-207. doi: $10.1037 / \mathrm{a} 0022415$

Cody, P. A., Farr, R. H., McRoy, R. G., Ayers-Lopez, S. J., \& Ledesma, K. J. (2017). Youth perspectives on being adopted from foster care by lesbian and gay parents: Implications 
for families and adoption professionals. Adoption Quarterly, 20, 98-118.

doi:10.1080/10926755.2016.1200702

Colaner, C. W., \& Soliz, J. (2015). A communication-based approach to adoptive identity: Theoretical and empirical support. Communication Research, 44, 611-637. doi: $10.1177 / 0093650215577860$

Cox, M. J., \& Paley, B. (1997). Families as systems. Annual Review of Psychology, 48, 243-267. doi:10.1146/annurev.psych.48.1.243

Cummings, E. M., Koss, K. J., \& Davies, P. T. (2015). Prospective relations between family conflict and adolescent maladjustment: Security in the family system as a mediating process. Journal of Abnormal Child Psychology, 43, 503-515. doi:10.1007/s10802-0149926-1

Davies, P. T., Coe, J. L., Martin, M. J., Sturge-Apple, M. L., \& Cummings, E. M. (2015). The developmental costs and benefits of children's involvement in interparental conflict. Developmental Psychology, 51, 1026-1047. doi:10.1037/dev0000024

Davies, P. T., Martin, M. J., \& Cummings, E. M. (2018). Interparental conflict and children's social problems: Insecurity and friendship affiliation as cascading mediators. Developmental Psychology, 54, 83-97. doi:10.1037/dev0000410

Davies, P. T., Martin, M. J., \& Sturge-Apple, M. L. (2016). Emotional security theory and developmental psychopathology. In D. Cicchetti (Ed.), Developmental psychopathology: Theory and method (Vol. 1, 3rd ed.) (pp. 199-264). Hoboken, NJ: John Wiley \& Sons. Del Giudice, M., Angeleri, R., \& Manera, V. (2009). The juvenile transition: A developmental switch point in human life history. Developmental Review, 29, 1-31. doi:10.1016/j.dr.2008.09.001 
Demby, K. P., Riggs, S. A., \& Kaminski, P. L. (2017). Attachment and family processes in children's psychological adjustment in middle childhood. Family Process, 56, 234249. doi:10.1111/famp. 12145

Diedenhofen, B. \& Musch, J. (2015). cocor: A comprehensive solution for the statistical comparison of correlations. PLoS ONE, 10, e0121945. doi:10.1371/journal.pone.0121945

El-Sheikh, M., Cummings, E. M., \& Reiter, S. (1996). Preschoolers' responses to ongoing interadult conflict: The role of prior exposure to resolved versus unresolved arguments. Journal of Abnormal Child Psychology, 24, 665-679. doi:10.1007/BF01670106

Farr, R. H. (2017). Does parental sexual orientation matter? A longitudinal follow-up of adoptive families with school-age children. Developmental Psychology, 53, 252-264. doi: $10.1037 / \operatorname{dev} 0000228$

Farr, R. H., Crain, E. E., Oakley, M. K., Cashen, K. K., \& Garber, K. J. (2016). Microaggressions, feelings of difference, and resilience among adopted children with sexual minority parents. Journal of Youth and Adolescence, 45, 85-104. doi:10.1007/s10964-015-0353-6

Farr, R. H., Flood, M. E., \& Grotevant, H. D. (2016). The role of siblings in adoption outcomes and experiences from adolescence to emerging adulthood. Journal of Family Psychology, 30, 386-396. doi:10.1037/fam0000173.

Farr, R. H., \& Goldberg, A. E. (2018). Sexual orientation, gender identity, and adoption law. Family Court Review, 56, 374-383. doi:10.1111/fcre.12354

Farr, R. H., \& Grotevant, H. G. (2019). Adoption. In B. Fiese (Ed.), APA Handbook of Contemporary Family Psychology (pp. 725-741). Washington, DC: American Psychological Association. 
Farr, R. H., \& Patterson, C. J. (2013). Coparenting among lesbian, gay, and heterosexual couples: Associations with adopted children's outcomes. Child Development, 84, 12261240. doi:10.1111/cdev.12046

Faul, F., Erdfelder, E., Lang A.-G., \& Buchner, A. (2007). G*Power 3: A flexible statistical analysis program for the social, behavioral, and biomedical sciences. Behavior Research Methods, 39, 175-191. doi:10.13758/BF03193146

Favez, N., Widmer, E. D., Frascarolo, F., \& Doan, M. (2019). Mother-stepfather coparenting in stepfamilies as predictor of child adjustment. Family Process, 58, 446-462. doi:10.1111/famp. 12360

Fedewa, A. L., Black, W. W., \& Ahn, S. (2015). Children and adolescents with same-gender parents: A meta-analytic approach in assessing outcomes. Journal of GLBT Family Studies, 11, 1-34. doi:10.1080/1550428X.2013.869486

Feinberg, M. E., Kan, M. L., \& Goslin, M. C. (2009). Enhancing coparenting, parenting, and child self-regulation: Effects of family foundations 1 year after birth. Prevention Science, 10, 276-285. doi:10.1007/s11121-009-0130-4

Gates, G. J. (2013). Demographics and LGBT health. Journal of Health and Social Behavior, 54, 72-74. doi:10.1177/0022146512474429

Gianino, M., Goldberg, A., \& Lewis, T. (2009). Family outings: Disclosure practices among adopted youth with gay and lesbian parents. Adoption Quarterly, 12, 205-228. doi:10.1080/10926750903313344

Goldberg, A. E., \& Smith, J. Z. (2016). Predictors of race, adoption, and sexual orientation related socialization of adoptive parents of young children. Journal of Family Psychology, 30, 397-408. doi:10.1037/fam0000149 
Goldberg, S. K., \& Conron, K. J. (2018). How many same-sex couples in the U.S. are raising children? The Williams Institute. Retrieved from https://williamsinstitute.law.ucla.edu/ research/parenting/how-many-same-sex-parents-in-us/

Golombok, S., Blake, L., Slutsky, J., Raffanello, E., Roman, G. D., \& Ehrhardt, A. (2018). Parenting and the adjustment of children born to gay fathers through surrogacy. Child Development, 89, 1223-1233. doi:10.1111/cdev.12728

Golombok, S., Mellish, L., Jennings, S., Casey, P., Tasker, F., \& Lamb, M. E. (2014). Adoptive gay father families: Parent-child relationships and children's psychological adjustment. Child Development, 85, 456-468. doi:10.1111/cdev.12155

Grotevant, H. D., McRoy, R. G., Wrobel, G. M., \& Ayers-Lopez, S. (2013). Contact between adoptive and birth families: Perspectives from the Minnesota/Texas Adoption Research Project. Child Development Perspectives, 7, 193-198. doi:10.1111/cdep.12039

Grotevant, H. D., Rueter, M., Von Korff, L., \& Gonzalez, C. (2011). Post-adoption contact, adoption communicative openness, and satisfaction with contact as predictors of externalizing behavior in adolescence and emerging adulthood. Journal of Child Psychology \& Psychiatry, 52, 529-536. doi:10.1111/j.1469-7610.2004.00269.x

Guan, X., \& Li, X. (2017). A cross-cultural examination of family communication patterns, parent-child closeness, and conflict styles in the United States, China, and Saudi Arabia. Journal of Family Communication, 17, 223-237. doi:10.1080/15267431.2017.1293062

Harris, E. A. (2017, June 20). Same-sex parents still face legal complications. NY Times. Retrieved from https://www.nytimes.com/2017/06/20/us/gay-pride-lgbtq-same-sexparents.html

Horstman, H. K., Colaner, C. W., \& Rittenour, C. E. (2016). Contributing factors of adult 
adoptees' identity work and self-esteem: Family communication patterns and adoptionspecific communication. Journal of Family Communication, 16, 263-276.

doi:10.1080/15267431.2016.1181069

Jarosz, A. F., \& Wiley, J. (2014). What are the odds? A practical guide to computing and report reporting Bayes Factors. Journal of Problem Solving, 7, 1-9. doi:10.7771/19326426.1167

Keller, P. S., Cummings, E. M., Peterson, K. M., \& Davies, P. T. (2009). Marital conflict in the context of parental depressive symptoms: Implications for the development of children's adjustment problems. Social Development, 18, 536-555.

doi:10.1111/j.1467-9507.2008.00509.x

Kohler, J. K., Grotevant, H. D., \& McRoy, R. G. (2002). Adopted adolescents' preoccupation with adoption: The impact on adoptive family relationships. Journal of Marriage and Family, 64, 93-104. doi:10.1111/j.1741-3737.2002.00093.x

Le Mare, L., \& Audet, K. (2011). Communicative openness in adoption, knowledge of culture of origin, and adoption identity in adolescents adopted from Romania. Adoption Quarterly, 14, 199-217. doi:10.1080/10926755.2011.608031

Lindahl, K. M., \& Malik, N. M. (2001). The System for Coding Interactions and Family Functioning. In P. K. Kerig \& K. M. Lindahl (Eds.), Family observational coding systems: Resources for systemic research (pp. 77-91). Mahwah, NJ: Lawrence Erlbaum Associates Publishers.

Minuchin, P. (1988). Relationships within the family: A systems perspective on development. In R. A. Hinde \& J. Stevenson-Hinde (Eds.), Relationships within families: Mutual influences (pp. 7-26). New York: Oxford University Press. 
Raudenbush, S. W., \& Bryk, A. S. (2002). Hierarchical linear models: Applications and data analysis methods (2 ${ }^{\text {nd }}$ ed.). Newbury Park, CA: Sage.

Raudenbush, S. W., Bryk, A. S., Cheong, Y. F., Congdon, R., \& du Toit, M. (2011). HLM7: Hierarchical Linear and Nonlinear Modeling. Lincolnwood, IL: Scientific Software International, Inc.

Richmond, M. K., \& Stocker, C. M. (2006). Associations between family cohesion and adolescent siblings' externalizing behavior. Journal of Family Psychology, 20, 663-669. doi:10.1037/0893-3200.20.4.663

Robin, A. L., \& Foster, S. L. (1989). Negotiating parent-adolescent conflict: A behavioral-family systems approach. New York: Guilford.

Rueter, M. A., \& Koerner, A. F. (2008). The effect of family communication patterns on adopted adolescent adjustment. Journal of Marriage and Family, 70, 715-727. doi:10.1111/j.1741-3737.2008.00516.x

Schoppe, S. J., Mangelsdorf, S. C., \& Frosch, C. A. (2001). Coparenting, family process, and family structure: Implications for preschoolers' externalizing behavior problems. Journal of Family Psychology, 15, 526-545. doi:10.1037/0893-3200.15.3.526

Shigeto, A., Mangelsdorf, S. C., \& Brown, G. L. (2014). Roles of family cohesiveness, marital adjustment, and child temperament in predicting child behavior with mothers and fathers. Journal of Social and Personal Relationships, 31, 200-220.

doi:10.1177/0265407513490586

Singh, R. \& Nayak, J. K. (2016). Parent-adolescent conflict and choice of conflict resolution strategy: Familial holiday planning. International Journal of Conflict Management, 27, 88-115. doi:10.1108/IJCMA-04-2014-0025 
Tan, T. X., \& Jordan-Arthur, B. (2012). Adopted Chinese girls come of age: Feelings about adoption, ethnic identity, academic functioning, and global self-esteem. Children and Youth Services Review, 34, 1500-1508. doi:10.1016/j.childyouth.2012.04.001

Teubert, D., \& Pinquart, M. (2010). The association between coparenting and child adjustment: A meta-analysis. Parenting: Science and Practice, 10, 286-307. doi:10.1080/15295192.2010.492040

Tieman, W., van der Ende, J., \& Verhulst, F. C. (2008). Young adult international adoptees' search for birth parents. Journal of Family Psychology, 22, 678-687. doi:10.1037/a0013172

Van Doorn, M. D., Branje, S. T., \& Meeus, W. J. (2008). Conflict resolution in parent-adolescent relationships and adolescent delinquency. The Journal of Early Adolescence, 28, $503-$ 527. doi:10.1177/0272431608317608

van Gelderen, L., Gartrell, N., Bos, H., \& Hermanns, J. (2013). Stigmatization and resilience in adolescent children of lesbian mothers. Journal of GLBT Family Studies, 5, 268-279. doi:10.1080/15504280903035761

Von Korff, L., \& Grotevant, H. D. (2011). Contact in adoption and adoptive identity formation: The mediating role of family conversation. Journal of Family Psychology, 25, 393-401. doi:10.1037/a0023388

Wrobel, G. M., Grotevant, H. D., \& McRoy, R. G. (2004). Adolescent search for birthparents: Who moves forward? Journal of Adolescent Research, 19, 132-151. doi:10.1177/0743558403258125 
Table 1

Demographic Information by Family Type

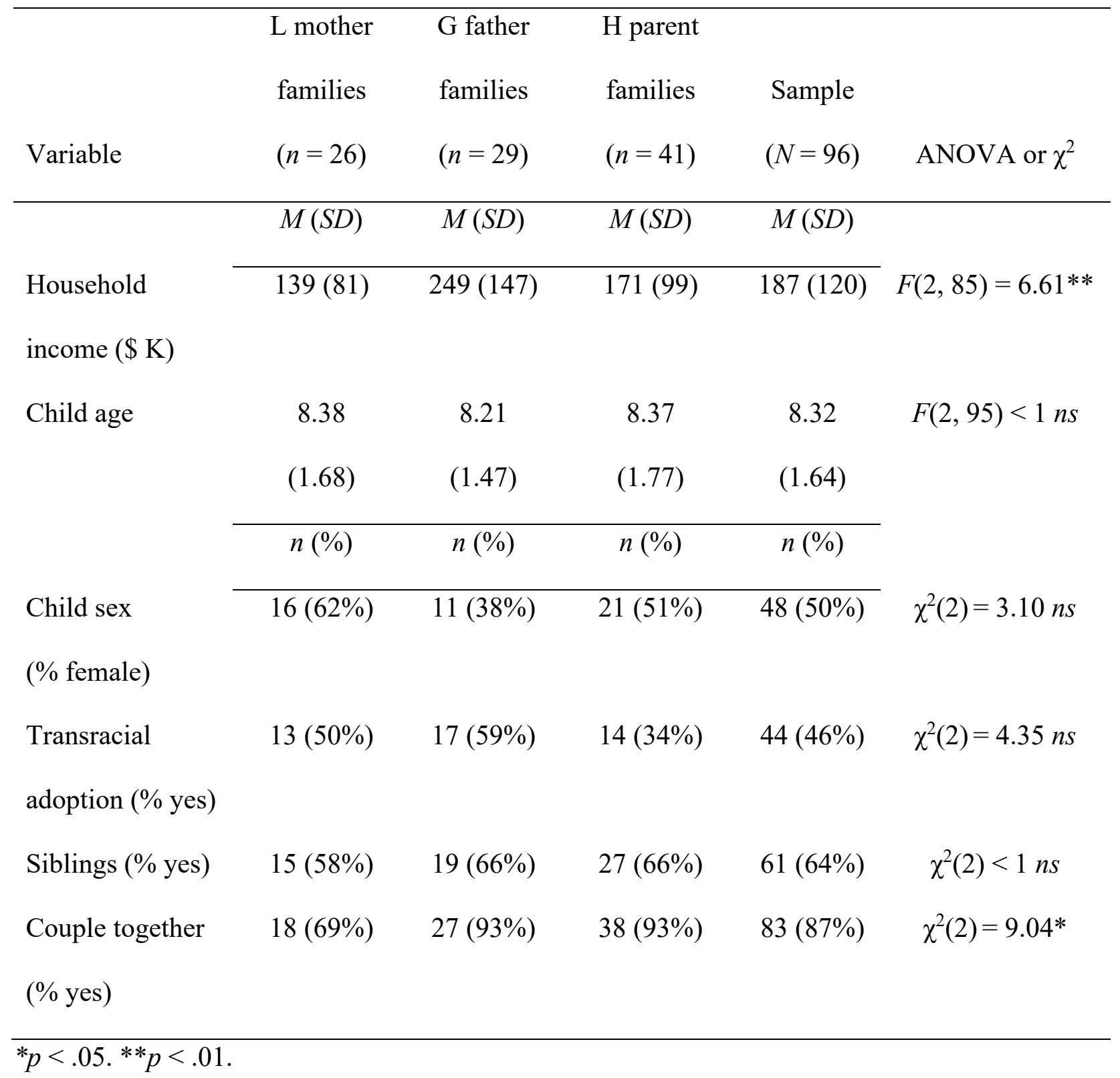

Note. Demographic characteristics for Wave 1 were originally reported in Farr and Patterson (2013), and for Wave 2, in Farr (2017). 
Table 2

Descriptive Results (Means, Standard Deviations, ANOVA, and Bayesian Analyses) by Family Type

\begin{tabular}{|c|c|c|c|c|c|c|}
\hline & $\begin{array}{c}\text { L mother } \\
\text { families }(n=26)\end{array}$ & $\begin{array}{c}\text { G father } \\
\text { families }(n=29)\end{array}$ & $\begin{array}{c}\text { H parent } \\
\text { families }(n=41)\end{array}$ & $\begin{array}{l}\text { Sample } \\
(N=96)\end{array}$ & ANOVA & $\begin{array}{l}\text { Bayes } \\
\left(\mathrm{BF}_{01}\right)^{\mathrm{a}}\end{array}$ \\
\hline Family & $n=23$ & $n=27$ & $n=40$ & $N=90$ & & \\
\hline Negativity/ conflict & $2.48(.79)$ & $2.37(1.11)$ & $2.53(.85)$ & $2.47(.91)$ & $F(2,87)<1 n s$ & 8.12 \\
\hline Cohesiveness & $3.61(.84)$ & $3.59(.97)$ & $3.28(.88)$ & $3.46(.90)$ & $F(2,87)=1.46 n s$ & 3.01 \\
\hline Positive affect & $3.00(.74)$ & $3.15(.91)$ & $2.83(1.01)$ & $2.97(.92)$ & $F(2,87)=1.02 n s$ & 4.29 \\
\hline Child & $n=25$ & $n=29$ & $n=41$ & $N=95$ & & \\
\hline \multirow[t]{2}{*}{ Externalizing $^{\mathrm{b}}$} & $50.10(11.15)$ & $50.02(10.04)$ & $49.50(9.18)$ & $49.82(9.88)$ & $F(2,92)<1 n s$ & 9.93 \\
\hline & $n=24$ & $n=26$ & $n=38$ & $N=88$ & & \\
\hline Positive adoption affect ${ }^{\mathrm{c}}$ & $4.42(.17)$ & $4.36(.35)$ & $4.31(.34)$ & $4.36(.30)$ & $F(2,85)<1 n s$ & 4.65 \\
\hline \multirow[t]{2}{*}{ Negative experiences ${ }^{\mathrm{c}}$} & $2.05(.58)$ & $2.22(.71)$ & $2.33(.74)$ & $2.22(.69)$ & $F(2,85)=1.23 n s$ & 3.66 \\
\hline & $n=24$ & $n=25$ & $n=38$ & $N=87$ & & \\
\hline Preoccupation $^{\mathrm{d}}$ & $4.01(1.85)$ & $3.63(1.69)$ & $3.40(1.84)$ & $3.64(1.80)$ & $F(2,84)<1 n s$ & 4.91 \\
\hline
\end{tabular}

abayes factors reflect the likelihood of obtaining the null vs. alternate model. ${ }^{\mathrm{b}}$ Means represent average scores of parents' reports for the same child within families. ${ }^{\mathrm{c}}$ Means reflect scores from items on a 1-5 scale. ${ }^{\mathrm{d}}$ Means reflect scores from items on a 1-7 scale. 
Table 3

Associations among Variables of Interest

\begin{tabular}{lccccccc} 
Family observations & 1. & 2. & 3. & 4. & 5. & 6. & 7. \\
\cline { 2 - 7 } 1. Negativity/conflict & - & - & - & - & - & - & - \\
2. Positivity & $-.49 * * *$ & - & - & - & - & - & - \\
3. Cohesiveness & & & & & & & \\
& $-.60 * * *$ & $.62 * * *$ & - & - & - & - & -
\end{tabular}

\section{Parent reports}

4. Child externalizing score $\quad .20^{\dagger} \quad-.08 \quad-.29 * *$

(Parent A)

5. Child externalizing score $\quad .30^{* *} \quad-.18^{\dagger} \quad-.34^{* *} \quad .66^{* * *}$ (Parent B)

\section{Child reports}

6. Positive adoption affect $\quad \begin{array}{lllllll}-.23 * & .30 * * & .23 * & .02 & -.003 & -\end{array}$

7. Negative adoption

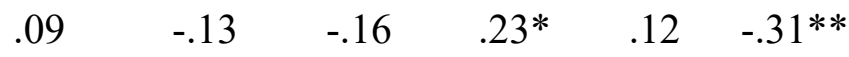
experiences

8. Adoption preoccupation $\quad \begin{array}{llllllllll} & -.07 & .05 & .25^{*} & -.08 & -.03 & .09 & -.06\end{array}$ ${ }^{\dagger} p<.10 . * p<.05 . * * p<.01 . * * * p<.001$. 